\title{
Políticas Públicas e a pessoa com deficiência no Estado do Amapá
}

\author{
Dilma Terezinha da Silva Barreto \\ Universidade Estadual do Ceará - UECE \\ Emanuel Freitas da Silva \\ Universidade Estadual do Ceará - UECE
}

\begin{abstract}
Resumo
O presente estudo enfatiza a importância da inserção da pessoa com deficiência no mundo do trabalho, fazendo uma trajetória das fases e paradigmas dentro de uma contextualização histórica do processo de inclusão profissional no Estado do Amapá. 0 objetivo para o desenvolvimento deste estudo foi analisar o processo de inclusão no mundo do trabalho das pessoas com deficiência, através de pesquisa bibliográfica, com analises do sistema histórico de emprego no Estado e de documentos como: leis, decretos, portarias e normas, como também programas e projetos implementados nos sistemas sociais referentes ao acesso e a permanência dessa parte da sociedade nos postos de trabalho nos setores públicos enfatizando a Secretaria de Trabalho, emprego e Empreendedorismo do Amapá (SETE-AP), e pesquisa de campo com entrevista semiestruturada. Os sujeitos da pesquisa foram 16 pessoas, sendo dez do sexo masculino e seis do sexo feminino, entre cursistas e profissionais atuantes na SETE. Esta pesquisa pontuou aspectos pertinentes e de extrema importância para a acessibilidade e cidadania da pessoa com deficiência.
\end{abstract}

Palavra-chave pessoa com deficiência; política pública para o trabalho; inclusão; qualificação profissional.

\begin{abstract}
The present study emphasizes the importance of inserting people with disabilities in the world of work, making a trajectory of the phases and paradigms within a historical context of the process of professional inclusion in the State of Amapá. The objective for the development of this study was to analyze the process of inclusion of people with disabilities in the world of work, through bibliographic research, with analyzes of the historical employment system in the State and of documents such as: laws, decrees, ordinances and norms, such as also programs and projects implemented in social systems regarding access and permanence of this part of society in jobs in the public sectors, emphasizing the Secretariat of Labor, Employment and Entrepreneurship of Amapá (SETE-AP), and field research with semi-structured interview. The research subjects were 16 people, ten male and six female, among students and professionals working at SETE. This research pointed
\end{abstract}


out pertinent and extremely important aspects for the accessibility and citizenship of people with disabilities.

Key-word disabled person; public policy for work; inclusion; professional qualification.

\section{Introdução}

O Estado do Amapá aparece em terceiro lugar em relação ao número de pessoas com deficiência desempregadas, com uma taxa que chega a $20,2 \%$ dessa população, correspondendo a quase o dobro da média nacional, anexada em 12, 7\% nos primeiros três meses de 2019. Esse crescimento na taxa de desemprego aconteceu em 14 dos 27 estados conforme números colhidos pela Pesquisa Nacional por Amostra de Domicílios (PNAD). Analisa-se o quanto essas dificuldades aumentam para aqueles que nasceram com alguma deficiência ainda que estejam qualificados a competição a partir do discurso da meritocracia torna-se desleal.

O objetivo geral deste artigo é analisar as políticas inclusivas na perspectiva da habilitação e mundo do trabalho, como estão sendo realizadas na Secretaria de Trabalho e Empreendedorismo, voltadas às pessoas com deficiência, essas políticas são de fundamental importância na reserva e garantia dos direitos, esse conhecimento proporcionará a análise do que está sendo cumprindo a partir de aportes legais, os encaminhamentos que estão sendo feitos no sentido da fiscalização e efetivação dessas políticas na Secretaria de Trabalho e empreendedorismo (SETE).

Este texto é fruto da pesquisa de mestrado em Planejamento e Políticas Públicas da Universidade Estadual do Ceará sob a orientação do Professor Doutor Emanuel Freitas que instigados pelas inquietações perante os processos de inclusão no mundo do trabalho para pessoas com deficiência analisamos por meio de relevantes pesquisas bibliográficas o processo histórico das políticas de emprego e renda no Estado do Amapá, utilizamos também a pesquisa documental aonde destacamos a Lei Brasileira de Inclusão os Projetos de implementação dos setores públicos realizados pela SETE e dos dados estatísticos do Instituto Brasileiro de Geografia e Estatísticas (IBGE). Posteriormente partimos para a pesquisa de campo com entrevista semiestruturada aos profissionais e cursistas participantes o que possibilitou uma análise mais contundente do tema.

\section{Contexto da experiencia avaliada}

O Estado do Amapá, cuja capital é Macapá, localiza-se no extremo norte do Brasil, na faixa da fronteira da Amazônia oriental, nos dados do Censo 2010 apresentou uma população de 669.526 pessoas e em 2018 está estimada em 829.494 pessoas, possui 16 munícipios sendo eles: Macapá, Santana, Amapá, Mazagão, Laranjal do Jari, Vitoria do Jari, Calçoene, Oiapoque, Tartarugalzinho, Ferreira Gomes, Porto Grande, Pedra Branca do Amapari, Itaubal do Piriri, Pracuúba, Cutias do Araguari e Serra do Navio.

As duas maiores cidades do Estado do Amapá em terminações de dinâmica populacional e econômica, oferta de serviços, geração de emprego e renda e para onde atraem contingentes populacionais de regiões mais próximas são Macapá e Santana. Ferreira (2018, p.33) afirma que esse contingente populacional continua a crescer apresentando desafios às entidades públicas sobre o qual as estruturas urbanas não acompanharam e (nem acompanham) este crescimento. Neste viés, se para as pessoas sem 
deficiência os transtornos são demasiados com problemas de infraestrutura, para as pessoas com deficiência (PcD), cuja barreiras estruturais estão diretamente ligadas a sua qualidade de vida, deslocamento e sobretudo acesso aos meios de habilitação e emprego, essas esfinges tornam-se dificuldades reais no estado. E ratifica que:

As cidades do Estado do Amapá constituem espaços urbanos altamente desestruturados, sem uma política eficaz, com um planejamento fragmentado, que ocorre mais por pressão social e política, com o surgimento de espaços urbanos informais que desemboca em assentamentos em condições desastrosas, sem a menor condição de serviços e equipamentos urbanos. (TOSTES, 2011).

A centralização dos empregos e serviços na área urbana de Macapá-AP, acarreta elevadas concorrências para formação e qualificação profissional, no entanto como relata Tostes (2011) de forma desestruturada, com política ineficaz, prevalecendo os esforços dos grupos sociais que almejam políticas públicas em especial as PcDs. É possível analisar a ampliação dos problemas sociais, dos quais poucas oportunidades de trabalho e renda, bem como a deficiência e/ou insuficiência de transporte público, e precariedade em serviços educacionais, notoriamente geram o aumento das desigualdades. Corrobora nesta assertiva o autor:

(...) refere-se que a grande concentração de população em áreas urbanas amplia os problemas sociais, que se traduzem em poucas oportunidades de emprego e de renda, habitação insuficiente e inadequada, deficiente transporte público, saneamento deficiente, incipientes serviços educacionais e de saúde. (SOUZA et al, 2014, p.33).

Essas referências sobre emprego e economia no estado refletem de forma duas vezes mais agravadas para as $\mathrm{PcD}$, pois, deixando as "adaptações" de lado, estas não resolvem por completo a falta de políticas públicas para as necessidades especiais com as quais devem ser corrigidas com propostas diretas para a melhoria e garantia de vida igualitária dentro das diferenças para os indivíduos. Diante disto é possível averiguar as iniciativas também do processo educacional neste estado.

O conselho de Educação do Território Federal do Amapá aprovou em 13 de outubro de 1975, a resolução no 02/75 - CETA que estabelecia as normas sobre a Educação dos Deficientes Mentais (educáveis e treináveis) e um ano depois criou-se a Associação de Pais e Amigos Excepcionais - APAE.

No ano de 1976, a Associação de Pais e Amigos dos Excepcionais - APAE foi fundada em Macapá sob a direção do Sr. José Maria Frota, sendo a mesma destinada ao atendimento de alunos com deficiência mental treinável e Síndrome de Down. (SILVA e SENA, 2015, p.128).

Vale ressaltar que o primeiro local a fundar a APAE foi o Estado do Rio de Janeiro em 1954, ou seja somente vinte e dois anos (22) depois o Amapá experimentou novas 
atitudes para avançar nas políticas para as Pessoas com Deficiência. É perceptível que as várias escolas especiais criadas neste período apresentavam um cunho assistencialista, com traços estigmatizados e ainda excludentes do mundo, da sociabilidade; separando os educandos de sua classe a fim de prover conhecimentos com metodologias impróprias, objetivando a integração apenas.

O quadro abaixo apresenta uma estimativa do total das pessoas com Deficiência no Brasil comparativamente a quantidade no Estado do Amapá conforme dados divulgados pelo IBGE (2010). Objetiva a percepção mais clara sobre a realidade do Estado mediante a pesquisa a ser concretizada

Quadro 1 - Estimativa do total de pessoas com deficiência no Estado do Amapá

\begin{tabular}{|c|c|c|c|c|c|}
\hline $\begin{array}{l}\text { Estimativa } \\
\text { entre Brasil }\end{array}$ & BRASIL & $\begin{array}{c}\text { ESTADO DO } \\
\text { AMAPÁ }\end{array}$ & \multicolumn{3}{|c|}{ Grau de dificuldade } \\
\hline $\begin{array}{c}\text { e Estado do } \\
\text { Amapá }\end{array}$ & Total & $\begin{array}{l}\text { Pelo menos } \\
\text { uma das } \\
\text { deficiências } \\
\text { investigadas }\end{array}$ & $\begin{array}{c}\text { Não consegue } \\
\text { de modo } \\
\text { algum }\end{array}$ & $\begin{array}{c}\text { Grande } \\
\text { dificuldade }\end{array}$ & $\begin{array}{c}\text { Alguma } \\
\text { dificuldade }\end{array}$ \\
\hline População & 190.755 .799 & 669.526 & 528.624 & 6.056 .684 & 29.206 .180 \\
\hline PcD & 45.623 .910 & 158.749 & $\begin{array}{c}/ / / / / / / / / / / \\
/ / /\end{array}$ & $\begin{array}{c}/ / / / / / / / / / / \\
/ /\end{array}$ & $\begin{array}{c}/ / / / / / / / / \\
/ / / / /\end{array}$ \\
\hline Intelectual & 2.617 .025 & 6.402 & $\begin{array}{c}1 / / / / / / / / / / \\
/ / / /\end{array}$ & $\begin{array}{c}/ / / / / / / / / / \\
/ / /\end{array}$ & $/ / / / / / / / / / / /$ \\
\hline Física & $\begin{array}{c}/ / / / / / / / / / \\
/ / /\end{array}$ & $\begin{array}{c}/ / / / / / / / / / / \\
/\end{array}$ & 740.456 & 3.701 .790 & 8.831 .723 \\
\hline Auditiva & 45.623 .910 & 158.749 & 786 & 4.757 & 22.689 \\
\hline Visual & 45.623 .910 & 158.749 & 1.334 & 24.749 & 16.482 \\
\hline
\end{tabular}

Fonte: Elaborado pelos autores.

A SETE tem como função institucional formular, coordenar e implementar políticas públicas de emprego, trabalho e renda, primando pela inserção produtiva dos indivíduos com idade economicamente ativa, priorizando as demandas de maior vulnerabilidade social, importa frisar que as pessoas com deficiência estão inseridas neste processo. As ações são desenvolvidas por meio de duas coordenadorias. A coordenadoria de empreendedorismo tem como responsabilidade desenvolver atividades voltadas ao fomento do empreendedorismo no Estado, para isso possui núcleos com diferentes funções seguindo a proposta com o associativismo e economia solidária, o incentivo aos micro e pequenos investimentos, o fomento do crédito assistido e o desenvolvimento do artesanato, dentro da dinâmica do trabalho informal.

Outra coordenadoria é a do trabalho, à ela compete o atendimento integrado ao trabalhador, uma das ações prioritárias é a promoção da qualificação profissional e a inserção do público alvo da secretaria ao mundo do trabalho, dentre estes públicos estão os apenados e egressos do sistema penal, negros, indígenas, pessoas com deficiência, jovens de 
16 a 24 anos, e trabalhadores acima dos quarenta anos. 0 estímulo e articulação com órgãos governamentais ou não governamentais no sentido de educação empreendedora e qualificação para o trabalho informal é significativo no Estado do Amapá, pois percebe-se que a renda está atrelada aos concursos públicos ou aos serviços, não há visibilidade nem incentivo em outros setores, mas é possível considerar um estado em desenvolvimento nas competências da indústria, dos meios tecnológicos e do empreendedorismo.

\section{Metodologia}

A pesquisa que serviu como base para este artigo integrou um projeto de análise das perspectivas da habilitação e mundo do trabalho na Secretaria de Estado do Trabalho e Empreendedorismo no Amapá. Para a realização desta, todos os sujeitos foram previamente informados da realização do processo metodológico e comprovaram consenso através da assinatura do Termo de Consentimento Livre e Esclarecido.

As indagações sobre as políticas públicas inclusivas acerca da qualificação e inserção ao mundo do trabalho, questões sobre acessibilidade, capacitação dos ministrantes dos cursos, parceiros e instituições empreendedoras e a visão dos cursistas com deficiência quanto as efetividades das ações permearam a metodologia para análises mais precisas sobre a atividade laboral, o perfil dos entrevistados é diversificado e possuem diferentes faixa-etárias. Os sujeitos têm entre 18 e 54 anos, entre 1 a 25 anos de atuação. São dez sujeitos do sexo masculino, sendo 4 (quatro) cursistas com deficiência e seis do sexo feminino das quais, 2(duas) cursistas com deficiência, totalizando 16 entrevistados. Apresenta-se a seguir um quadro referente aos dados descritos.

\section{Quadro 2- Caracterização dos sujeitos da pesquisa, Instituições parceiros/demandas}

\begin{tabular}{|c|c|c|c|c|}
\hline Código & Idade & Sexo & $\begin{array}{c}\text { Formação/ tempo de } \\
\text { serviço }\end{array}$ & Cargo / Função \\
\hline Q.P-1 & 37 & $\mathrm{M}$ & $\begin{array}{l}\text { Graduado em Biologia } \\
\text { Especialização em coaching } \\
\text { educacional }\end{array}$ & $\begin{array}{l}\text { Diretor/ Gerente SINE/AP } \\
\text { Atuação: } 7 \text { anos }\end{array}$ \\
\hline Q.P-2 & 54 & $\mathrm{~F}$ & $\begin{array}{lll}\begin{array}{l}\text { Licenciatura } \\
\text { psicologia }\end{array} & \text { plena } & \text { em } \\
& & \end{array}$ & $\begin{array}{l}\text { Professora Orientação para o } \\
\text { Trabalho. } \\
\text { Atuação } 25 \text { anos }\end{array}$ \\
\hline Q.P-3 & 43 & $\mathrm{~F}$ & Graduado em Administração & $\begin{array}{l}\text { Técnico da coordenação de } \\
\text { empreendedorismo } \\
\text { Atuação: } 4 \text { anos }\end{array}$ \\
\hline Q.P-4 & 33 & $\mathrm{~F}$ & $\begin{array}{l}\text { Graduada em Administração } \\
\text { Especialista em } \\
\text { gerenciamento de empresas }\end{array}$ & $\begin{array}{l}\text { Secretária de Estado/SETE } \\
\text { Atuação: } 1 \text { ano }\end{array}$ \\
\hline Q.P-5 & 39 & $\mathrm{M}$ & $\begin{array}{l}\text { Graduado em História } \\
\text { Especialização em gerência } \\
\text { de projetos }\end{array}$ & $\begin{array}{l}\text { Secretário adjunto/SETE } \\
\text { Atuação: } 2 \text { anos e } 6 \text { meses }\end{array}$ \\
\hline Q.P-6 & 44 & $\mathrm{M}$ & $\begin{array}{l}\text { Graduado em Pedagogia } \\
\text { Especialista } \\
\text { administração de empresas }\end{array}$ & $\begin{array}{l}\text { Instrutor SENAI/AP } \\
\text { Atuação: 8anos }\end{array}$ \\
\hline Q.P-7 & 45 & $\mathrm{~F}$ & $\begin{array}{l}\text { Graduada em Pedagogia } \\
\text { Especialização em Educação } \\
\text { Especial e Inclusiva }\end{array}$ & $\begin{array}{l}\text { Instrutora Orientações para o } \\
\text { Trabalho } \\
\text { Atuação:12 anos }\end{array}$ \\
\hline
\end{tabular}




\begin{tabular}{|c|c|c|c|c|}
\hline Q.P-8 & 31 & $\mathrm{M}$ & Graduado em Contabilidade & $\begin{array}{l}\text { Atendente/Casa do Trabalhador } \\
\text { Autônomo } \\
\text { Atuação: } 3 \text { anos }\end{array}$ \\
\hline Q.P-9 & 46 & M & $\begin{array}{l}\text { Ensino Médio } \\
\text { Profissionalizante } \\
\text { (administração) }\end{array}$ & $\begin{array}{l}\text { Atendente Super-Fácil } \\
\text { Santana/AP } \\
\text { Atuação: } 9 \text { anos }\end{array}$ \\
\hline Q.P-10 & 39 & $\mathrm{M}$ & $\begin{array}{l}\text { Graduação em Secretariado } \\
\text { Executivo } \\
\text { Especialista em Gestão } \\
\text { educacional }\end{array}$ & $\begin{array}{l}\text { Atendente Super-fácil Macapá- } \\
\text { AP } \\
\text { Atuação: } 3 \text { anos }\end{array}$ \\
\hline Q.P-C11 & 52 & $\begin{array}{l}\text { F-pcd } \\
\text { Deficiência } \\
\text { intelectual }\end{array}$ & EJA $-2^{a}$ etapa & $\begin{array}{l}\text { Cursista-Secretaria de } \\
\text { saúde/serviços gerais } \\
\text { Atuação: } 24 \text { anos }\end{array}$ \\
\hline Q.P-C12 & 46 & $\begin{array}{l}\text { M-pcd } \\
\text { Paralisia } \\
\text { Cerebral }\end{array}$ & $\begin{array}{l}\text { Graduado em Pedagogia } \\
\text { Especialização em Educação } \\
\text { Especial e Inclusiva }\end{array}$ & $\begin{array}{l}\text { Cursista Serviços Gerais } \\
\text { Atuação: } 17 \text { anos }\end{array}$ \\
\hline Q.P- C13 & 27 & $\begin{array}{l}\text { M-pcd } \\
\text { Autista }\end{array}$ & Ensino Médio (cursando) & $\begin{array}{l}\text { Artesão/ Programa de } \\
\text { empreendedorismo da SETE }\end{array}$ \\
\hline Q.P-C14 & 18 & $\begin{array}{l}\text { M -pcd } \\
\text { Deficiência } \\
\text { intelectual }\end{array}$ & EJA- 3a etapa & $\begin{array}{l}\text { Cursista-Estágio remunerado } \\
\text { Atuação: } 6 \text { meses }\end{array}$ \\
\hline Q.P-C15 & 27 & $\begin{array}{l}\text { F -pcd } \\
\text { Deficiência } \\
\text { física }\end{array}$ & $\begin{array}{l}\text { Ensino fundamental } \\
\text { (incompleto) }\end{array}$ & $\begin{array}{l}\text { Artesã / Programa de } \\
\text { empreendedorismo/SETE } \\
\text { Atuação: } 3 \text { anos }\end{array}$ \\
\hline Q.P-C16 & 39 & $\begin{array}{l}\text { M -pcd } \\
\text { Deficiência } \\
\text { física }\end{array}$ & Ensino médio & Cursista/ desempregado \\
\hline
\end{tabular}

Fonte: Elaborado pelos autores

Na coleta de dados primeiramente foi realizado o contato e observações in loco dos funcionários específicos da SETE e das instituições parceiras, entrevistas semiestruturadas foram gravadas nos próprios locais de trabalho. Para os cursistas com deficiência, a entrevista foi marcada em momento posterior ao curso. Com o intuito de preservar a identidade dos sujeitos optou-se pelo emprego das iniciais " $Q$ " de qualificação e " $P$ " profissional e cargo/função correspondente para os funcionários da SETE e parceiros, e para os cursistas permaneceu as iniciais Q.P e acrescentou " $C$ " de cursista, prevalecendo o cargo/função exercidos.

\section{3- Pesquisa realizada}

Conforme descrito sobre os processos metodológicos, as indagações principais foram como as ações voltadas para as pessoas com deficiência estavam sendo implementadas na SETE, onde através do Sistema Nacional de Emprego (SINE), órgão do Governo federal gerenciado pelos estados por meio de repasses de verbas anuais para a execução das atividades concernentes a qualificação e inserção primeiramente no banco de dados e posteriormente nas vagas disponíveis de emprego.

Sobre o trabalhador pcd só existe um programa específico para o mesmo denominado dia "D", ocorre em (1) um dia do segundo semestre do ano, onde são realizadas ações com as empresas cadastradas e disponibilizadas vagas para a inserção direta no mundo do trabalho, atividades de atendimento à saúde, emissão de documentos, palestras 
motivacionais, apresentações teatrais e musicais. Nesta data os atendentes do SINE, superfácil e o sistema " $S$ " concentram-se em um único espaço no sentido de atender à demanda com deficiência.

O trabalhador pcd ele é incluído no geral como forma de qualificação de a única coisa (sic), o único programa que temos aqui para o pcd é o dia "D", que acontece uma vez no ano e é nacional. (Q.P-ATENDENTE SUPER-FÁCIL).

A ausência de políticas públicas inclusivas no passado consolidava o desconhecimento dos indivíduos para a situação das minorias excluídas, a adequação de 1 (um) dia nacional para lembrar da importância de ações de inserção dos pcd's poderia esmorecer aqueles que buscam conquistas de direitos e planejamentos eficazes para consolidar o que está prescrito nas leis. No entanto, no Estado do Amapá, onde o deslocamento e as informações só ganharam agilidade após o advento das tecnologias de comunicação, a implementação e participação do dia "D" é uma conquista inquestionável e importa divulgar para o aumento dos participantes e possibilidade de distribuição nos municípios e não somente em um ponto de concentração da capital.

Sabe-se que a efetiva inclusão está associada não ao exclusivismo de ações para os indivíduos com deficiência, incluir de fato traduz a inserção por meio do respeito às diferenças, e através dos direitos humanos viabiliza-se recursos para a qualidade de vida conforme a necessidade especial dos sujeitos. 0 dia "D" faz-se pertinente em virtude do longo período de segregação vivido por esse grupo de pessoas, e embora tenha ocorrido avanço na legalização de políticas públicas, vivencia-se atitudes de discriminação e preconceito por parte de representantes empresariais em minorar a capacidade laboral dos sujeitos.

Os cursos de qualificação são organizados geralmente de acordo com a demanda dentro da oferta de empregos, os mais comuns estão no setor de serviços ou vendedor de comércio.

[..] a gente vive infelizmente é de comércio (sic) e de serviços não temos grandes indústrias, precisa ter um incentivo fiscal a mais para as empresas virem se instalar aqui, para poder se desenvolver mais enquanto estado, essas vagas de empregos que a gente tem aqui ou é de vendedor do comércio ou é de serviços, aí vai para os serviços gerais, o padeiro, o caixa, o mecânico, a babá, então são coisas que precisamos melhorar. (Q.P- GERENTE SINE/AP)

De fato, no Estado do Amapá a renda advém dos trabalhadores efetivos municipais, estaduais e federais, a movimentação comercial dá-se predominantemente a partir do pagamento desses segmentos, as empresas que se interessam em instalar-se no estado normalmente desistem em virtude dos elevados custos com fretes e deslocamento que ainda ocorre através de balsas em percurso lento, isto impossibilita o desenvolvimento industrial. Os setores1 que mais cresceram nos períodos da realização desta pesquisa foram a construção civil com uma variação de empregos de 12,93\% mensais e a agropecuária com

1 Verificar anexo: A Evolução do Emprego por setor de atividade econômica no Amapá- Abril/2019.(MTECADASTRO GERAL DE EMPREGADOS E DESEMPREGADOS-LEI 4923/65). 
2,24\% na variação mensal, motivo pelo qual a SETE ter ofertado 6 (seis) cursos de qualificação na área de construção civil em parceria com o SENAI/AP.

O Benefício de Prestação Continuada da Assistência Social2 (BPC) é apontado como um dos entraves entre as respostas dos entrevistados das instituições. Uma vez que a pessoa com deficiência recebe esse benefício deixa de qualificar-se ou ter interesse em avanços na aprendizagem.

Anteriormente a 2011, o BPC representava um obstáculo para a inserção de pcd no espaço do trabalho formal, pois uma vez admitida, a pessoa com deficiência beneficiária passava a ter o benefício cancelado e, caso desejasse requerê-lo seria necessário fazer todo o processo novamente, inclusive a perícia médica. Dessa forma, a família optava por não ingressar no mundo do trabalho devido a valores serem os mesmos normalmente pagos no benefício (um salário mínimo mensal).

A Lei no 12.470/11 regulamenta aspectos do BPC, dentre eles: a possibilidade de não extinção do benefício para os que optaram por trabalhar, mas sua suspensão durante a vigência de contrato formal de trabalho pelo prazo máximo de 2(dois) anos, proporcionando um aspecto importante na legislação que em suma representa a viabilidade da presença das pessoas com deficiência na habilitação e mundo do trabalho.

No geral trabalhador pcd específico a empresa só vem aqui quando é notificada pelo Ministério ou tá em risco de ser multado aí ele corre no SINE, disponibiliza a vaga pede logo um comprovante né (sic) de que ele disponibilizou a vaga do SINE e aí acontece aquilo tudo, o trabalhador vai pra empresa eles ficam enrolando, enrolando e depois eles dão uma desculpa pro Ministério, diz que não contratou e é isso que acontece na realidade. (Q.P.- GERENTE SINE/AP)

A resistência das empresas em contratar é uma dificuldade que persiste, embora as instituições públicas e algumas privadas por meio da responsabilidade social atuem de modo que "são realizadas reuniões para sensibilizar sobre o potencial laborativo (sic) das pcd candidatos às vagas e informações sobre as diferenças entre deficiências e incapacidade" (Q.P.-2). Quando as empresas são notificadas pelo descumprimento da lei de cotas corre o risco de sofrer punição com pagamento de multa na qual a partir de $1^{\mathrm{o}}$ de janeiro de 2019 houve reajuste, variando de $\mathrm{R} \$ 2.411,28$ (dois mil quatrocentos e onze reais e vinte e oito centavos) a 241.126,88 (duzentos e quarenta e um mil e cento e vinte e seis reais e oitenta e oito centavos), de acordo com o grau de descumprimento, conforme Portaria n⿳9口9, de 15 de janeiro de 2019 do Ministério da Economia.

\footnotetext{
2 O BPC é de caráter individual, não vitalício e intransferível, assegurando a transferência mensal de 1 salário mínimo ao idoso, com 65 anos ou mais, e à pessoa com deficiência, de qualquer idade. Para obter o valor os beneficiários devem comprovar não possuir meios de garantir o próprio sustento, e nem tê-lo provido por sua família, por meio da comprovação de renda mensal familiar per capita inferior a $1 / 4$ (um quarto) do salário mínimo vigente. Os dados do Ministério do Desenvolvimento Social e Combate à fome (MDS), no ano de 2016 (referência/março) forma pagos 4.276.577 BPCs no Brasil, dos quais 2.343.164 destinaram-se às pessoas com deficiência, cerca de 4,89\% e 1.933 .413 a idosos (3,92). Comparativamente com os dados de 2015 (referência/março), percebeu-se um aumento nas concessões os quais os números apontam 4.242.697 benefícios pagos, sendo 2.323.794 para PCD e 1.918 .903 a idosos. (Site http://mds.gov.br/area-deimprensa/dados, Visualizado em 14/06/2019).
} 


\section{Resultado final}

Um aspecto básico contido na Constituição Federal Brasileira é o direito à educação, as pessoas com deficiência sofriam e sofrem com o preconceito e a exclusão, a falta de aceitação nas escolas básicas é uma problemática que ocorre constantemente, isso acarreta uma sequência de perdas, atrasos educacionais.

0 processo de assistência por meio das atividades empreendedoras para o trabalho autônomo está crescendo no Estado do Amapá, dada o excesso de desocupação, novas alternativas para o fomento de renda estão sendo implementadas e para a pessoa com deficiência funciona como uma terapia. Segundo informações do técnico responsável, as peças produzidas manualmente e o ato da construção das mesmas estão sendo utilizadas pela entidade AMA -AP Associação de Pais e Amigos Autistas do Amapá, no sentido de exercitar as técnicas de atenção e concentração das pessoas com autismo.

A constante qualificação é necessária para todo o indivíduo em idade economicamente ativa, pois possibilita o crescimento nos âmbitos da sociabilidade, da atualização laboral contribuindo nos aspectos de uma possível concorrência de colocação de emprego. É importante para a pessoa com deficiência estímulos diversos, as políticas públicas de inserção no mundo do trabalho indicam no artigo 36 da Lei Brasileira de Inclusão ser dever do poder público implementar serviços e programas de habilitação profissional e de reabilitação, sendo respeitados a livre escolha, o interesse e a vocação de cada um.

\section{Proposições}

As análises a partir das perspectivas de habilitação e mundo do trabalho da pessoa com deficiência possibilitaram o entendimento de que existem questões que se convergem dentro da própria legislação acerca dos proponentes de direitos, uma das quais é o Benefício de Prestação Continuada dentro da Assistência Social, onde foi unânime a ideia do mesmo ser um dos motivos da falta de procura dos pcd para a qualificação profissional, uma vez que o benefício paga o mesmo valor que uma empresa pagaria, o correspondente a um salário mínimo. Para superar as barreiras atitudinais, as ações devem partir de mudanças dentro das instituições, com metodologias de sensibilização, seminários informativos sobre a história, dificuldades e vantagens de oportunizar atitudes de respeito às pessoas com deficiência.

A tomada de decisões que beneficiem a equidade de direitos perpassa pelo conhecimento do outro, pela desmistificação de conceitos e atitudes historicamente criados no processo de construção dos sujeitos, tratar os indivíduos sob uma visão homogênea produz consequentemente relações sociais de desigualdade porque ninguém é igual, são as diferenças e as diversidades que nos tornam sujeitos de valores.

Concernente aos estudos realizados, foi possível entender o protagonismo da tomada de consciência social no avanço das políticas públicas inclusivas sob o viés das organizações como articulação inicialmente de entidades com um objetivo comum, neste caso, a inclusão das pessoas com deficiência onde os movimentos ganharam visibilidade política e causaram efetivas transformações, sobretudo conjunturais dentro das legislações internacionais, nacionais e regionais. 


\section{Referências bibliográficas}

BRASIL. Constituição Federal brasileira. Brasília - DF, 1988.

Política Nacional de Educação Especial na Perspectiva da Educação Inclusiva. Brasilia: SEESP/MEC, 2008. Disponível em: $<$ http://portal.mec.gov.br/arquivos/pdf/politicaeducespecial.pdf>. Acesso em: $13 \mathrm{dez}$. 2018.

. Lei 13.146, de 06 de julho de 2015. Institui a Lei Brasileira de inclusão da pessoa com deficiência (Estatuto da pessoa com deficiência). Diário Oficial [da] República Federativa do Brasil, Brasília,6 jul. 2015.

Resolução CNE/CEB № 2, de 11 de setembro de 2001. Institui Diretrizes Nacionais para a Educação Especial na Educação Básica. Diário Oficial [da] República Federativa do Brasil, Brasília, 11 set. 2001. Disponível em: <http://portal.mec.gov.br/cne/arquivos/pdf/CEB0201.pdf>. Acesso em: 13 dez. 2017.

CARDOSO, L.M.G. Pessoas com deficiência e inclusão no mercado de trabalho: um estudo sobre lei de cotas, conflitos e cont(r)atos. Brasília: EdUnB, 2016.

DUARTE, R. Entrevistas em pesquisas qualitativas. Educar, Curitiba, v.6, n.24, p. 213-225, jul. 2004.

INSTITUTO BRASILEIRO DE GEOGRAFIA E ESTATÍSTICA - IBGE. Síntese de Indicadores Sociais: uma análise das condições de vida da população brasileira. Rio de Janeiro: IBGE, 2009.

MANICA, L. E.; CALIMAN, G. A educação profissional para pessoas com deficiência: um novo jeito de ser docente. Brasília:Unesco, 2015.

MATOS, N.R.V. Inclusão perversa: uma reflexão sobre o sentido do trabalho para pessoas com deficiência. Curitiba: Appris, 2017. Inclusão: acessibilidade no lazer, trabalho e educação. Revista Nacional de Reabilitação (Reação), São Paulo, v.12, n.7, p.10-16, mar. /abr.2003. Inclusão: construindo uma sociedade para todos. 8. ed. São Paulo:[s.n],2010. Nada sobre nós, sem nós: da integração à inclusão-Parte 1. Revista Nacional de Reabilitação, v.10, n.57, p.8-16, jul. /ag.2005.

SANTOS, K.P. Políticas de emprego e renda no Amapá: avanços e perspectivas. PRACS: Revista de Humanidades do curso de ciências sociais da UNIFAP. Macapá, v.4, n.3, p.159-173, dez.2010.

SOUZA, C. "Estado do Campo" da pesquisa em políticas públicas no Brasil. Revista brasileira de ciências sociais, v.18, n.51, p.44-49, fev. 2003. 